\title{
Normative approaches and activism in global bioethics
}

\author{
Bert Gordijn ${ }^{1} \cdot$ Henk ten Have ${ }^{2}$
}

Published online: 23 June 2015

(C) Springer Science+Business Media Dordrecht 2015

In her paper on "Global justice, capabilities approach and commercial surrogacy in India" Saravanan (2015) shows there is a significant contrast between the entitlements of surrogate mothers in India and the US. Surrogate mothers in India lack many of the rights and provisions that are perfectly normal in the US. In fact, Saravanan argues that a good deal of "surrogacy procedures in India are a violation of basic human rights, dignity and freedom ..." (Saravanan 2015). In the US, in contrast, surrogate mothers have a “... social support group, insurance for multiple pregnancies, maternity benefits, life insurance, psychological support, compensation for all expenses and loss of employment and representation by an attorney among many other rights and benefits" (Saravanan 2015).

Saravanan's paper clearly demonstrates that the phenomenon of commercial surrogacy crosses national borders. Next to transnational commercial surrogacy, globalisation has triggered many other bioethical issues that transcend the territories of individual national states. Examples are medical tourism, organ trade, brain-drain of health care workers and researchers, humanitarian interventions, international drug trials, access to pharmaceuticals, benefit sharing, biopiracy, environmental pollution and intellectual property. Enhanced mobility, improved infrastructure, better transportation and communication technologies have triggered numerous intrinsically international bioethical issues. NGOs, global journalism, new social media, blogs and all sorts of social activist organi-

Bert Gordijn

bert.gordijn@dcu.ie

Dublin City University, Dublin, Ireland

2 Duquesne University, Pittsburgh, PA, USA zations increasingly draw attention to these issues. These developments prompt two important questions concerning global bioethics.

\section{Normative approaches in global bioethics}

What is the best normative approach to tackle international bioethical issues? In an earlier contribution we have argued that a normative approach that is closely aligned with human rights discourse is, on balance, advantageous (Gordijn and ten Have 2014). One of the most important advantages is that human rights discourse is fairly well known worldwide and enjoys a great degree of acceptance (Andorno 2009; Ashcroft 2010; Baker 2001; Fenton and Arras 2010; Gordijn and ten Have 2014; Gordon 2012). In fact, it is difficult to name any other normative approach that people all over the globe are more familiar with and that is more accepted.

A second important benefit of human rights discourse is the clout it has. Not only does bioethics' alignment with the human rights movement facilitate a more effective impact on real world issues and policies (Arras and Fenton 2009; Fenton and Arras 2010; Gordijn and ten Have 2014). In addition, bioethics' proximity to human rights strengthens a connection to law making (Gordijn and ten Have 2014), thus facilitating what Ashcroft has called "policy bioethics" in contrast to "academic bioethics" (Ashcroft 2010, 643).

However, there is no reason to be dogmatic about the preferred normative approach in tackling issues of global bioethics. As the debate is likely to continue, it might yield more sophisticated insights about the distinctive advantages and disadvantages of different normative approaches. This then leads to the second question. 


\section{Activism in global bioethics}

To what extent should bioethicists become activists in the face of ethical shortcomings and global injustice? From the dawn of philosophy there have been ethicists who have seriously tried to have a positive impact on the world, informed by their ethical theories. Nowadays, several ethicists have started practical initiatives to trigger real world positive change. They have established altruistic organizations focused on reduction of extreme poverty and global inequities. Examples are Peter Singer's The Life you can save (see: http://www.thelifeyoucansave.org/) and Toby Ord's Giving what we can (see: https://www.giving whatwecan.org/).

A more practical social activist focus in bioethics, however, has not always been applauded. Benatar, for example, has argued that an activist agenda in bioethics might have an unfavorable impact on academic scholarship. Activism might increasingly instrumentalize academic scholarship, leading to more superficial and prejudicial assessments and a neglect of more sophisticated theoretical considerations (Benatar 2006).

However, this view does not adequately acknowledge that reflection and practice are intrinsically connected. As Hadot (1995) argued, philosophy has always been more a way of life than just an isolated, exclusively cerebral activity detached from the surrounding culture and social context. This is even truer for ethics as practical philosophy. The main challenge is how academic reflection is connected to social activism and vice versa, without assuming that these are two separated domains of activity. The field of human rights is an interesting example. Scholars in universities analyze and scrutinize human rights in general and specific rights such as the right to health in particular. Policy bodies such as the United Nations Human Rights Council monitor the application of human rights in various countries, and elaborate, for example, the right to health in specific domains, while NGOs such as Human Rights Watch report on implementation, address, blame and shame governments. One of the most successful stories of implementation of the right to health is due to an effective combination of academic researchers, social movements, and civil society in Brazil and South Africa, arguing for access to antiretrovirals for people with HIV/AIDS.
We believe that academic global bioethics should not only aim at elucidating and establishing moral insights. In addition, it should aim for social change and positive real world impacts. Why should global bioethics be any different than medicine, law and engineering? Thus global bioethics, and bioethics more generally, should combine academic engagement and real-world commitment. That bioethical reflection can yield positive real world changes is demonstrated by the development of research ethics committees after WWII. Without a doubt research participants are currently better protected than 50 years ago. Unfortunately this claim cannot be substantiated for each and every country on earth. There is still a lot of work to do. It seems to us that a good way to do this is by focusing on activities that are closely aligned with more traditional scholarly academic endeavors, such as promoting and improving education, protection, capacity building and policy development.

\section{References}

Andorno, R. 2009. Human dignity and human rights as a common ground for a global bioethics. Journal of Medicine and Philosophy 34(3): 223-240.

Arras, J., and E. Fenton. 2009. Bioethics and human rights: Access to health-related goods. Hastings Center Report 29: 27-38.

Ashcroft, R.E. 2010. Could human rights supersede bioethics? Human Rights Law Review 10(4): 639-660.

Baker, R. 2001. Bioethics and human rights: A historical perspective. Cambridge Quarterly of Healthcare Ethics 10: 241-252.

Benatar, D. 2006. Bioethics and health and human rights: A critical view. Journal of Medical Ethics 32(1): 17-20.

Fenton, E., and J. Arras. 2010. Bioethics and human rights: Curb your enthusiasm. Cambridge Quarterly of Healthcare Ethics 19: 127-133.

Gordijn, B., and H.A. ten Have. 2014. Future perspectives. Handbook of global bioethics, 829-844. Berlin: Springer.

Gordon, J.S. 2012. Human rights in bioethics-Theoretical and applied. Ethical Theory and Moral Practice 15(3): 283-294.

Hadot, Pierre. 1995. Qu'est-ce que la philosophie antique?. Paris: Gallimard.

Saravanan, S. 2015. Global justice, capabilities approach and commercial surrogacy in India. Medicine, Health Care and Philosophy 18(3): 195-207. 